\title{
Synthetic Epoxy-Pregnan Steroids: Effects on Anxiety Behavior in Rats
}

\author{
Rey $\mathbf{M}^{1}$, Ghini $\mathrm{AA}^{2}$ and Coirini $\mathbf{H}^{1,3, *}$
}

1Laboratorio de Neurobiologia, Instituto de Biología y Medicina Experimental (IBYME-CONICET), Vuelta de Obligado 2490, (C1428ADN), Ciudad Autónoma de Buenos Aires, Argentina.

2Departamento de Quimica Orgánica, Unidad de Microanálisis y Métodos Fisicos aplicados a Química Orgánica (UMYMFOR-CONICET) Facultad de Ciencias Exactas y Naturales, Universidad de Buenos Aires (FCEN-UBA), Pabellón 2, Ciudad Universitaria, Intendente Güiraldes 2160, (C1428EHA) Ciudad Autónoma de Buenos Aires, Argentina

3Departamento de Bioquimica Humana, Facultad de Medicina, Universidad de Buenos Aires, Paraguay 2155, 5to Piso, (C1121ABG) Ciudad Autónoma de Buenos Aires, Argentina.

"Corresponding author: Prof. Dr. Héctor Coirini, Laboratorio de Neurobiología, Instituto de Biología y Medicina Experimental (IBYME-CONICET), Vuelta de Obligado 2490, (C1428ADN), Ciudad Autónoma de Buenos Aires, Argentina, Tel: 54-11-4783-2869, ext. 250; Fax: 54-11-4786-2564; E-mail: hcoirini@ibyme.conicet.gov.ar

Receiving date: December 22, 2015, Accepted date: January 20, 2016, Publishing date: January 27, 2016

Copyright: @ 2016 Rey M, et al. This is an open-access article distributed under the terms of the Creative Commons Attribution License, which permits unrestricted use, distribution, and reproduction in any medium, provided the original author and source are credited.

\begin{abstract}

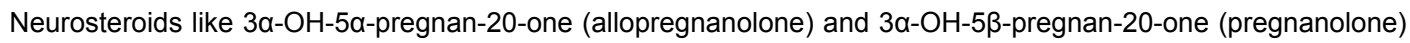
modulate the $y$-aminobutyric acid-A $\left(\mathrm{GABA}_{\mathrm{A}}\right)$ receptor function and produce several effects that can be considered for therapeutical pruposes like antidepressant and anxiolyticts, in a similar way to benzodiazepines. However, their rapid metabolism is a great disadvantage for medicinal treatments consideration. Synthetic steroid analogues with more bioavailability and stability arise like a solution to overcome these limitations. In previous studies, we evaluated the performance of a synthetic steroid group (Epoxies, similar to allopregnanolone and pregnanolone) throughout different assays in rat cerebral cortex and hippocampus, including neuroprotection and $G A B A_{A}$ receptor modulation obtaining promising results. Taking into account the anxiolytic effect of allopregnanolone and pregnanolone, in this work we evaluated the effect of an intracranial administration (in dorsal hippocampus) of two synthetic steroids, Epoxy 1 and Epoxy 2, in an anxiety animal model to provide knowledge about the possible in vivo effects of these steroids. Allopregnanolone and pregnanolone produced increases in vertical and horizontal exploration behaviors, interpreted as anxiolytic-like effects. However, the two Epoxies capable to modulate GABA $A_{A}$ receptor binding have no effect on anxiety at the dose evaluated. These features make them suitable for other therapeutical purposes where the anxiogenic behaviors are not involved.
\end{abstract}

Keywords: Neurosteroids; Synthetic analogues; Allopregnanolone; Pregnanolone; Open field

\section{Introduction}

Inside the central nervous system, the in situ synthesized steroids (neurosteroids, NS) are capable of modify the brain excitability [1,2]. Due to their chemical structure, the steroids may produce positive or negative modulations over receptors, like the $\gamma$-aminobutyric acid-A $\left(\mathrm{GABA}_{\mathrm{A}}\right)$ receptor [3,4]. Among the positive modulators of this receptor are two progesterone's metabolites: the $5 \alpha$-pregnane-3a-ol-20one (allopregnanolone, A) and its isomer $5 \alpha$-pregnane-3 $\beta$-ol-20-one (pregnanolone, P) [5]. In the last decades, the relevance of NS, like A and $\mathrm{P}$, also has been increasing due to their multiple roles in normal and pathological behavior, ageing processes, damaged tissue regeneration and neuroprotection [6-9]

The interest on these steroids arises specifically from their potential activity as anticonvulsants, anesthetics, anxiolytic or sedative-hypnotic agents [10] useful for the treatment of several neurological and psychiatric disorders [5]. But, the main limitation for the therapeutical administration of these NS is their rapid in vivo biotransformation to other metabolites. Therefore, synthetic steroids (SS) analogues with better bioavailability and efficacy have an important therapeutic potential in brain disorders, becoming an alternative approach for different pathologies $[11,12]$.

In the last decades, a significant increase around NS physiology and synthetic analogues development has been observed. The medicinal chemistry of neuroactive steroids (NAS) has been focused in the development of SS analogues preserving the absolute configuration of naturally occurring steroids. Structure/activity studies of the progesterone metabolites, indicate that the $3 a$-hydroxyl configuration is required for binding and activity maintenance [13], while modifications in some carbon atoms do not affect their functions [14-16]. In previous works we evaluated the performance of a SS group Epoxies (similar to $\mathbf{A}$ and $\mathbf{P}$ ) through different assays as well as neuroprotection and inhibition/stimulation binding of specific ligands of the $\mathrm{GABA}_{\mathrm{A}}$ receptor in rat cerebral cortex and hippocampus $[17,18]$. The main feature of these Epoxies is the presence of an oxygen bridge that holds the A/B angle of steroidal nucleus in a controlled way, conferring conformational restricted analogues [19]. In those studies, we demonstrated that, of all the Epoxies tested, the Epoxy 1 (3ahydroxy-2 $\beta, 19$-epoxy-5 $\alpha$-pregnan-20-one; A analogue) and the Epoxy 2 (3a-hydroxy-6,19-epoxypregn-4-ene-20-one; $\mathrm{P}$ analogue) produced the most similar effects to A and P $[17,18]$.

On the other hand, severe psychiatric conditions like anxiety and stress-related disorders affect daily performance in tasks and represent a high cost to public health. Thus, the search of new and improve therapeutical alternatives remains currently. Also, the fact that neurosteroidogenic agents lack benzodiazepine-like side effects shows promise in the treatment of anxiety and depression [11]. Administration of $\mathrm{A}$ or $\mathrm{P}$ produces anxiolytic, ataxic, hypnoticanesthetic and anticonvulsant effects as well as locomotor stimulation [5,20-30], being able to mimic the actions of benzodiazepines. Taking into account their effects as modulators of the $\mathrm{GABA}_{\mathrm{A}}$ receptor-ionchannel complex [5] mentioned before, the mechanism underlying their anxiolytic properties appears to be due to a potentiation of neural inhibition via this receptor [31-34]. Previous studies suggest that A 
increases the channel conductance of $\mathrm{GABA}_{\mathrm{A}}$ receptor-gated $\mathrm{Cl}^{-}$in hippocampal neurons, promoting anxiolytic-like effects [35-37]. This supports the hypothesis about the role that the dorsal (CA1) hippocampus area plays in emotional processes and NS modulation of anxiety and exploration. It has also been postulated that the dorsal region of this brain structure is involved in memory-related functions, whereas the ventral region mediates fear and anxiety responses[38]. In contrast to these anatomical and functional considerations, the recent results of Mòdol et al. [39] demonstrate that the dorsal (CA1) area of the hippocampus is also implicated in the modulation of anxietyrelated behaviors. Their studies indicate that the hippocampal administration of A produces an anxiolytic-like profile and also increases exploratory behavior, observed trough the enhancement of the number of entries into the open arms in the elevated plus-maze device. This suggests that CA1 region together with other brain structures (such as the amygdala or the medial septum) could be an important target for explaining the NS effects on exploration, anxiety, learning and memory [39]. $\mathbf{P}$ administration in the dorsal hippocampus or in the lateral septum also produces dose-dependent anxiolytic-like effects in several animal models [36]. Moreover, both steroids have shown a comparable potency eliciting anxiolytic effects $[24,27,31]$. In addition, the ability of these and other NS to decrease anxiety-induced behavior has been demonstrated in several tests such as light/dark transition, rearing events and open-field [22,34,40]. In fact, there is evidence that the anxiolytic action of progesterone is mediated by its reduced metabolites, $\mathbf{A}$ and $\mathbf{P}[41,42]$. Based in the previous results obtained with the Epoxies in the $\mathrm{GABA}_{\mathrm{A}}$ receptor modulation and the neuroprotective actions [17,18], and the anxiolytic-like effects mediated by $\mathrm{A}$ and $\mathrm{P}$, the aim of this work was to evaluate the effects of two of these SS (Epoxy 1 and Epoxy 2) administration over the animal behavior. These analysis were performed in an anxiety model (open-field test), assessing horizontal and vertical exploration and the anxiolytic-like effects; comparing results between synthetic and natural steroids.

\section{Materials and Methods}

\section{Steroids}

Two natural steroids (A and P) and two synthetic analogues, 3ahydroxy-1 $\beta, 11 \alpha$-epoxy-5a-pregnan-20-one (Epoxy 1, A analogue) [43] and 3a-hydroxy-6,19-epoxypregn-4-ene-20-one (Epoxy 2, P analogue) [44] were used. Steroid concentration used for microinfusion (6.7 $\mu \mathrm{g} / \mu \mathrm{l})$ was selected according to our previous results $[17,18]$. The solutions were prepared using cyclodextrin $30 \%$ in artificial cerebrospinal fluid (aCSF) as vehicle one hour before the administration.

\section{Experimental animals}

Ninety day old adult male Sprague Dawley rats (400 g; $\mathrm{n}=48$ ) were housed under standard laboratory conditions with a 12-h light-dark cycle, with food and water ad libitum on a temperature $\left(21^{\circ} \mathrm{C}\right)$ and humidity (40-70\%) controlled vivarium. The animal surgical procedures and treatments were evaluated by the Ethics Committee of the Instituto de Biología y Medicina Experimental (IBYME), CABA, Argentine, and approved according to the described on the protocol CE 040-Jun/2014, in accordance with guidelines defined by the European Community Council Directive (86/609/EEC) and the National Institutes of Health Guide for the Care and Use of Laboratory Animals.
Male rats were anesthetized with ketamine-xylazine $(40: 4 \mathrm{mg} / \mathrm{Kg}$ i.p.; Holliday, Richmond, Argentina) and placed in a stereotaxic apparatus (David Kopf Instruments, Tujunga CA, USA). Handmade 23 -gauge stainless steel cannulae with 30 -gauge removable inserts (dummy cannulae) were unilaterally implanted on the dorsal hippocampus using flat skull coordinates (anteroposterior, $-2.3 \mathrm{~mm}$; mediolateral, $\pm 1.6 \mathrm{~mm}$; dorsoventral, $2.8 \mathrm{~mm}$; from Bregma) according to the atlas Paxinos and Watson [45]. Three stainless steel screws and dental cement were used to fix the cannulae to the skull surface. After the surgery, animals were subcutaneously injected with a nonsteroidal anti-inflammatory (Meloxican $2 \mathrm{mg} / \mathrm{Kg}$ body weight, Boehringer Ingelheim, Argentina). A painkiller (Tramadol chlorhydrate $0.15 \mathrm{~g} / \mathrm{L}$; Finadiet SACIFI, Argentina) and an antibiotic (Enrofloxaxine $5 \mathrm{mg} / \mathrm{L}$; Afford SA, Argentina) were administered in the drinking water for the next 3 days.

Bilateral implants in some brain areas have been widely used to explore the anxiolytic and/or antidepressant like-effects [46-48]. Although, the choice of unilateral cannulation (with left/right alternations) performed in this work, was based in previous reports that described anxiolytic and antidepressant effects with unilateral microinjections of A [49] or progesterone [50], without behavioral differences between brain sides.

\section{Microinfusion procedure}

Animals were allowed to recover for 10 days before performing the behavioral trials. Vehicle (cyclodextrin $30 \%$ in aCSF) or steroids (A, P, Epoxy 1 and Epoxy 2; $2 \mu \mathrm{g}$ ) were administered in $0.3 \mu \mathrm{l}$ using a 30gauge injection needle connected by PC-40 tubing (Rivero SA, Argentina) to a $10 \mu \mathrm{l}$ glass syringe (Hamilton, Reno NV, USA; $0.1 \mu \mathrm{l} /$ $\mathrm{min})$. After the 3 minutes of microinfusion, the injection needle was kept in place for 1 additional minute to allow diffusion away from the cannula tip before the dummy cannula reposition. According to the condition, 5 groups of animals $(n=8)$ were established: Vehicle (cyclodextrin $30 \%$ in aCSF treatment), A (A treatment), P (P treatment), Epoxy 1 (Epoxy 1 treatment) and Epoxy 2 (Epoxy 2 treatment). Animals were hand restrained during all microinfusion procedure.

\section{Behavioral testing}

The open-field task [51,52] was used in accordance with the methods described by McCarthy et al. [53]. Behavioral testing occurred between 10:00 and 15:00h. The open-field device (housed in a dimly lit room with controlled temperature $21^{\circ} \mathrm{C}$ and humidity 40-70\%) consisted of $75 \mathrm{~cm}$ side squared box divided in 25 quadrants, with $30 \mathrm{~cm}$ height walls and an open roof. All animals were allowed to explore the device for 15 minutes (precondition test) one day before steroids microinfusion. At the next day, one minute after the dummy cannula relocation, animals were placed in the center of the device and were allowed to explore it for 300 seconds. The animal activity was videotaped with a digital camera suspended above the test apparatus. The behavioral parameters evaluated were: Freezing (duration of the animal in a completely stationary state), Active time (determined as total time test minus Freezing time), Line Crossing (number of grid lines crossed with all four paws), the frequency and duration of Grooming (when the animal licks and/or scratches itself while it stays still) and Rearing (when the animal stands up on its hind legs). After each trial, the apparatus was thoroughly cleaned with damp and dry towels to prevent olfactory cues. Behavioral videos were scored by two observers who were blind to the rat's treatment condition. 


\section{Histology}

At the end of the behavioral testing period, animals were rendered unconscious by $\mathrm{CO}_{2}$ and killed by decapitation. The brains were removed, frozen and stored at $-80^{\circ} \mathrm{C}$. Coronal sections $(40 \mu \mathrm{m}$ thick) obtained with a cryostat were mounted on subbed slides and stained with cresyl violet [54] for microscopic visualization of cannulae placements. The results from animals with accurately placed cannulae were used for the statistical analyses.

\section{Statistical analysis}

Statistical analyses were performed with commercial softwares GraphPad Prism (Graphpad Software Inc., v.4) and Statview (SAS Institute Inc. v5.0.1). The effects of intracranial microinfusions on the behavioral parameters were analyzed by a one-way ANOVA and comparisons between each steroid and vehicle were made by Newman-
Keuls post hoc test. Differences were considered significant when $\mathrm{p}<0.05$.

\section{Results}

\section{Histological analysis}

Cannulae tip localizations in the brain from those animals used for statistical analyses are schematically represented in Figure 1a. They were mainly placed on the dorsal (CA1) area of the hippocampus throughout the rostral-caudal extent. Cresyl violet staining was used for the visualization (Figure 1b). Cannulae distribution was more frequently positioned in $-2.40 \mathrm{~mm}$ anteroposterior; 1.3 and $2.4 \mathrm{~mm}$ mediolateral (left or right sides) and $2.6 \mathrm{~mm}$ dorsoventral from Bregma (Figure 1c; Paxinos and Watson [45]). Animals with bad placed cannulae $(\mathrm{n}=8)$ were discarded for statistical analyses. a

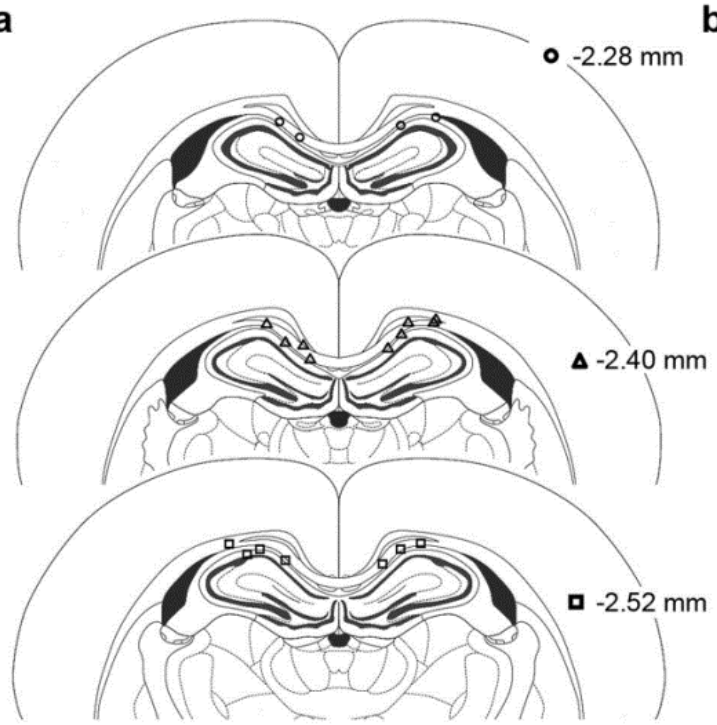

b

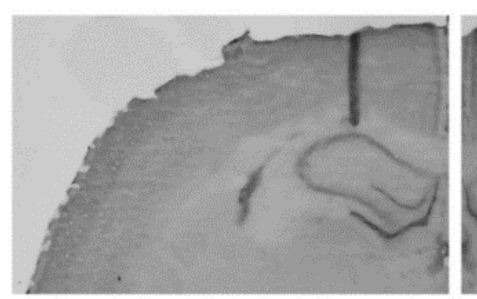

C

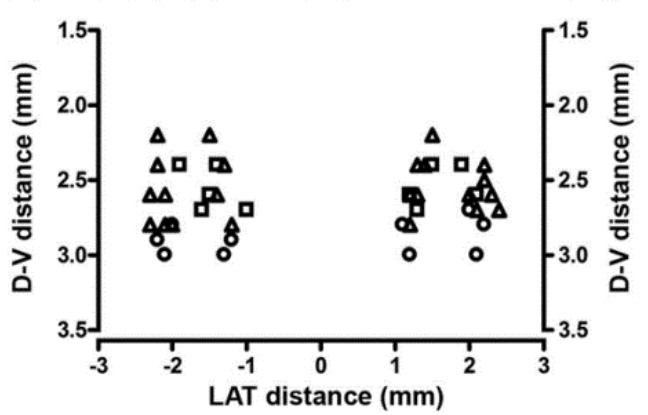

Figure 1: a Schematic representation of the well placed point of injection illustrating cannulae tip localizations throughout the rostral-caudal extent of the CA1 area of the hippocampus (anteroposterior, $-2.3 \mathrm{~mm}$; mediolateral, $\pm 1.6 \mathrm{~mm}$; dorsoventral, $2.8 \mathrm{~mm}$; from Bregma). Each symbol refers to different anteroposterior distance from Bregma according to Paxinos and Watson Atlas (1998; 0:n=11; $\Delta: \mathrm{n}=19 ; \mathbf{\square}: \mathrm{n}=10) . \mathrm{b}$ Representative photomicrographs of half coronal section, cresyl violet-stained, showing unilateral cannulae tip placements (left or right; magnification $\mathrm{x} 2$ ). c Cannulae distributions according to dorsoventral (D-V) and mediolateral (LAT) distance in mm.

\section{Active time}

The amount of time in which animals were in activity was determined as the total time of the test $(300 \mathrm{sec})$ minus the Freezing time (when the animals remain completely immobile). A significant increase on Active time was observed with $\mathrm{A}$ and $\mathrm{P}$ treatments compared to control $(143 \%$ and $147 \%$ respectively; $\mathrm{p}<0.05)$. These increases can be translated as an augmentation in total locomotor activity and horizontal and vertical explorations (Figure 2a). Although, no effects were observed with Epoxy 1 and Epoxy 2 treatments.

\section{Line crossing}

Ambulation was quantified as the number of grid lines crossed with all four paws within the $300 \mathrm{sec}$ of testing. $\mathrm{A}$ and $\mathrm{P}$ administrations produced significant increases of this parameter compared to vehicle
( $114 \%$ and $136 \%$ respectively; $\mathrm{p}<0.05$; Figure $2 \mathrm{~b}$ ). That can be interpreted as an increase in horizontal exploration activity, although no effects were observed with Epoxy 1 and Epoxy 2 administrations.

\section{Grooming and grooming ratio}

The frequency and duration of each occurrence (when the animal licks and scratches itself) was measured throughout the $300 \mathrm{sec}$ of testing. A significant increase in Grooming duration was observed only with P microinfusion (428\% compared to control; $\mathrm{p}<0.05$; Figure $2 \mathrm{c}$ ). However, no significant effects were observed on the duration of each Grooming event indicated by the "Grooming ratio" (defined like Grooming duration/Grooming frequency; Figure 2d). No effects were observed with the other three steroids in any of both variables. 
Citation: Rey M, Ghini AA, Coirini H (2016) Synthetic Epoxy-Pregnan Steroids: Effects on Anxiety Behavior in Rats. J Steroids Horm Sci 7:167.

Page 4 of 8

\section{Rearing and rearing ratio}

The frequency and duration of each occurrence (when the animal stands up on its hind legs) was measured in the $300 \mathrm{sec}$ of testing. Significant increases in total Rearing duration were observed with A and $\mathbf{P}$ treatments compared to vehicle $(265 \%$ and $271 \%$ respectively; $\mathrm{p}<0.05$; Figure $2 \mathrm{e})$. The increase of this parameter can be interpreted as an augmentation of vertical exploration activity, although no effects were observed on the duration of each Rearing event indicated by the "Rearing ratio" (defined like Rearing duration/Rearing frequency; Figure 2f). No effects were observed with Epoxy 1 and Epoxy 2 administrations in any of both parameters. a

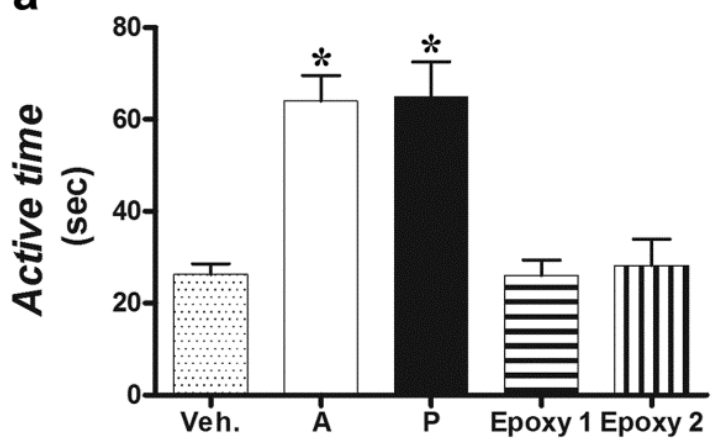

C

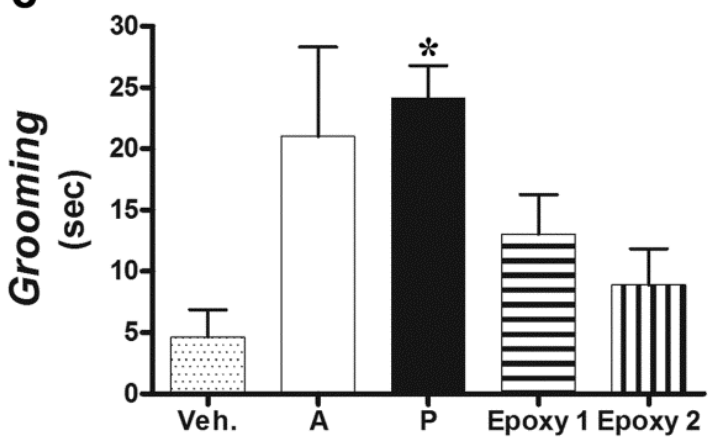

e

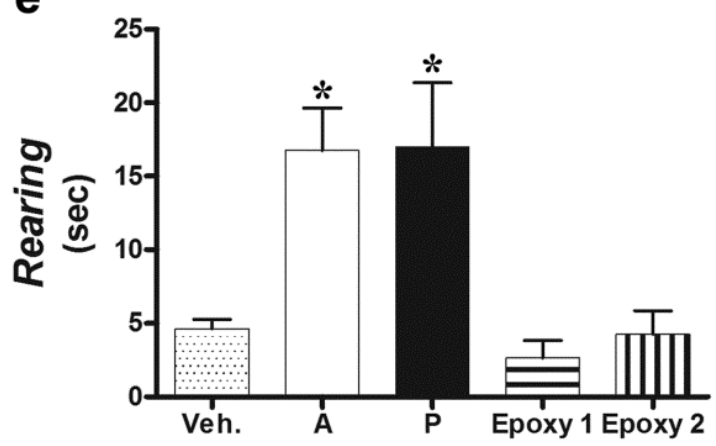

b

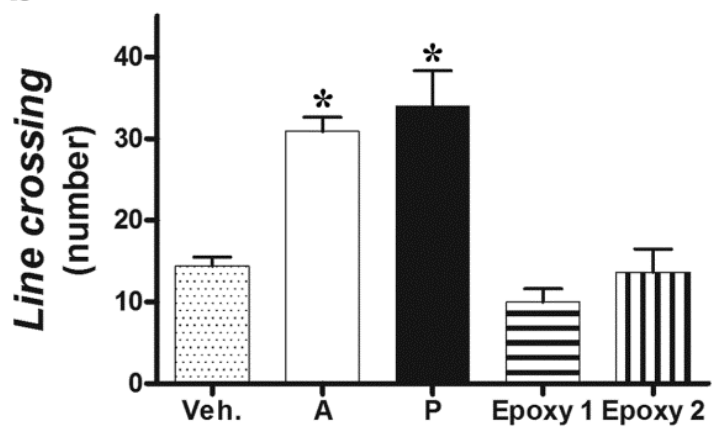

d

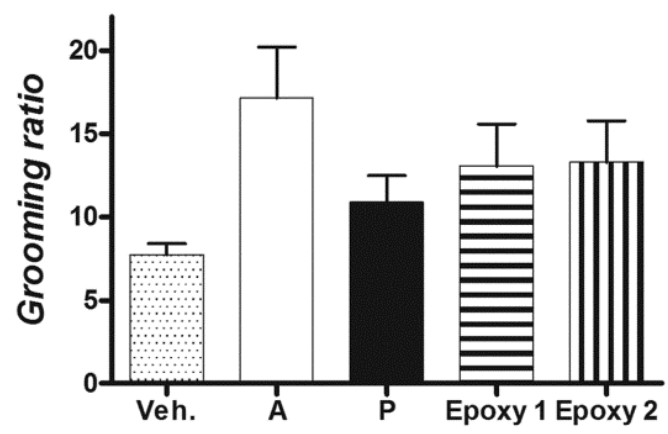

f

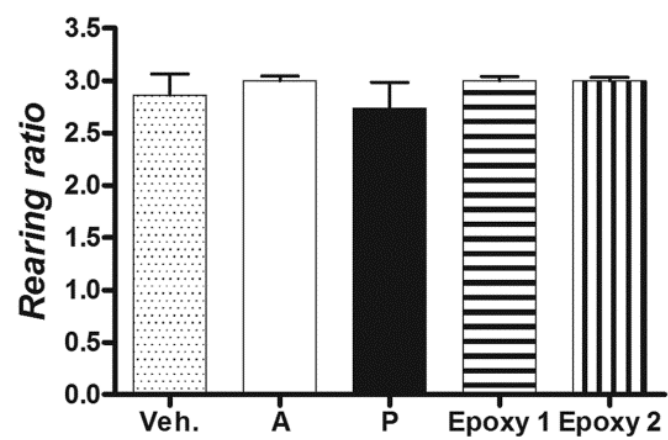

Figure 2: Unilateral microinfusion $(0.3 \mu \mathrm{l})$ on dorsal hippocampus of vehicle (Veh., cylcodextrin 30\% in aCSF) or steroid (A, P, Epoxy 1 and Epoxy 2; $2 \mu \mathrm{g}$ ) and changes in open-field behavioral parameters: a Active time (difference between total time test and freezing in sec) $\mathrm{b}$ Line crossing (number of grid lines crossed with all four paws), c Grooming (when the animal licks or scratches itself while stays still in sec) and $\mathrm{d}$ ratio (duration/frequency) and e Rearing (when the animal stands up on its hind legs in sec), and f ratio (duration/frequency). Significant effect was determined by one-way ANOVA: $\mathrm{F}_{\text {Active time }}(4,35)=15.3 ; \mathrm{p}<0.001, \mathrm{~F}_{\text {Line crossing }}(4,35)=18.2 ; \mathrm{p}<0.001, \mathrm{~F}_{\text {Grooming }}(4,35)=2.8 ; \mathrm{p}<0.05$, $\mathrm{F}_{\text {Grooming ratio }}(4,24)=1.1 ; \mathrm{p}=0.12, \mathrm{~F}_{\text {Rearing }}(4,35)=13.3 ; \mathrm{p}<0.001$ and $\mathrm{F}_{\text {Rearing ratio }}(4,28)=0.5 ; \mathrm{p}=0.75$, sub index in each $\mathrm{F}$ indicates the variable analysed. ${ }^{\star} \mathrm{p}<0.05$ Newman-Keuls post hoc test. 


\section{Correlation between Active time and Line crossing}

Analysis of Line crossing variable based on Active time, showed a positive correlation factor of 0.74 , when all the treatments were considered toghether (Figure $3 \mathrm{C}$ ). When this correlation was performed for each treatment, significant effects of $\mathbf{P}$ and its analogue,
Epoxy 2 (r2=0.77 and r2=0.69 respectively; Figure $3 \mathrm{P}$ and Figure 3 Epoxy 2) were observed, but with lower Active time for the Epoxy 2 than P. On the other hand, the Epoxy 1 showed similar pattern than its natural analogue $\mathrm{A}$ and vehicle, with no significant ANOVA $\mathrm{p}$ values (Figure 3).
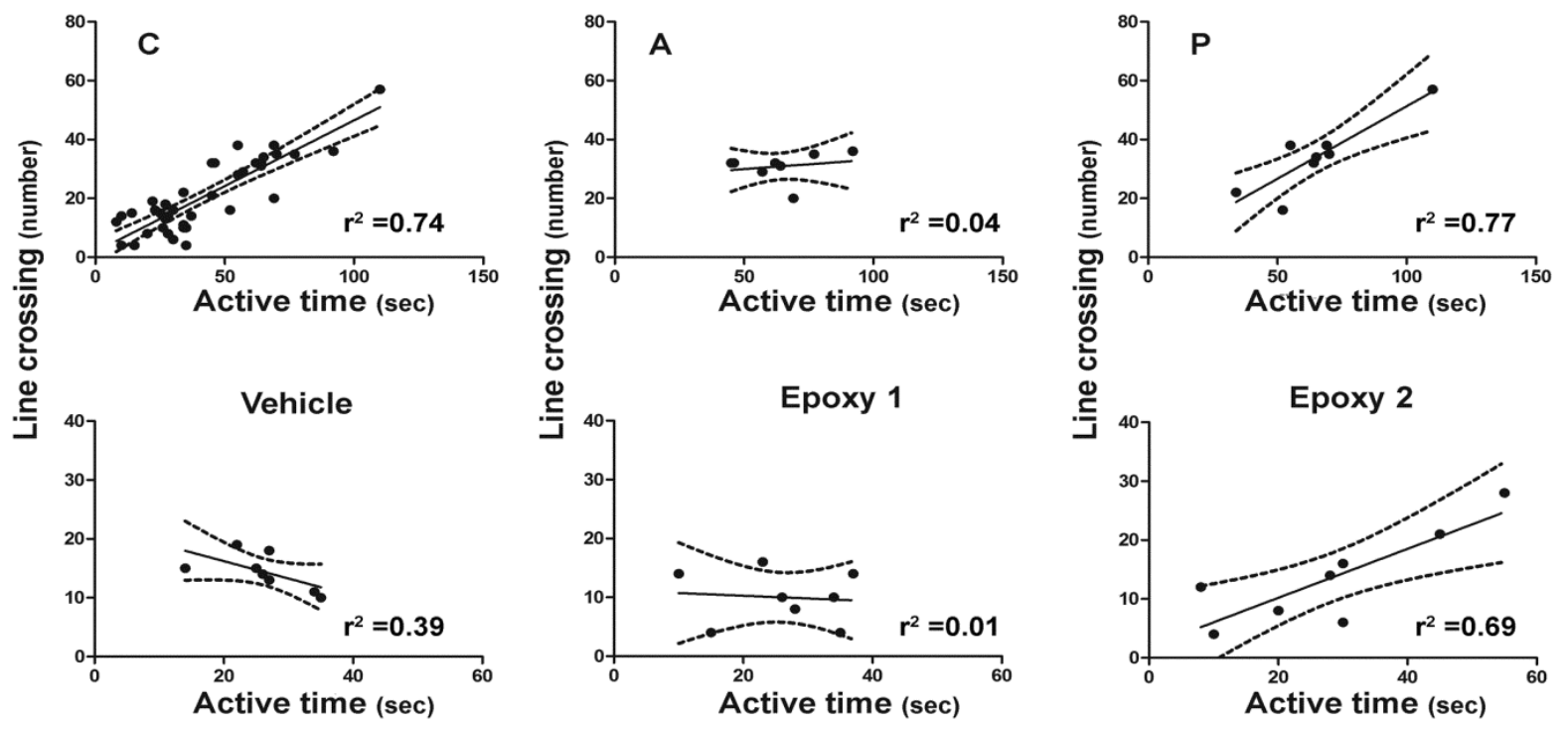

Figure 3: Correlation between Line crossing and Active time behavioral parameters, under all conditions together (C) or for each microinfusion treatment (Vehicle, A: allopregnanolone, P: pregnanolone, Epoxy 1 and Epoxy 2). Each point represents a value corresponding to an individual animal test. Correlation coefficients are showed in each panel. Significant effects were determined by one-way ANOVA: $\mathrm{F}_{\mathrm{C}}(1,40)=108.2 ; \mathrm{p}<0.0001, \mathrm{~F}_{\text {Vehicle }}(1,6)=3.9 ; \mathrm{p}=0.09, \mathrm{~F}_{\mathrm{A}}(1,6)=0.3 ; \mathrm{p}=0.62, \mathrm{~F}_{\mathrm{P}}(1,6)=20.5 ; \mathrm{p}=0.004, \mathrm{~F}_{\text {Epoxy } 1}(1,6)=0.1 ; \mathrm{p}=0.82$ and $\mathrm{F}_{\text {Epoxy } 2}$ $(1,6)=19.6 ; \mathrm{p}=0.01$, sub index in each $\mathrm{F}$ indicates the treatment analyzed. Dotted lines indicate the $95 \%$ confidence intervals.

\section{Discussion}

Anxiety is an unpleasant nervous state of inner restlessness. Although benzodiazepines and barbiturates are among the treatments of choice for this kind of pathologies, they may induce various side effects [55]. Their actions may be mediated by the $\mathrm{GABA}_{\mathrm{A}}$ receptor located within the hippocampal formation, which mediates postsynaptic inhibition [56].

Progesterone and its reduced metabolites, $\mathrm{A}$ and $\mathrm{P}$, were found to produce anxiolytic-like effects similar to benzodiazepines [36,57,58]. In the brain, in situ synthetized NS are capable of modulating neuronal excitability by rapid non-genomic actions [59] acting as potent modulators of $\mathrm{GABA}_{\mathrm{A}}$ receptor-mediated neurotransmission [5]. They can locally influence neuronal activity through their effects as paracrine messengers [60]. Thus, NS may have important effects on the regulation of the behavior in humans and in different murine models.

On the other hand, the hippocampal formation is important for the acquisition of short-term memory [61] and it has been also related to anxiety behaviors. Recently, reports described an association between dorsal hippocampus and the modulation of anxiety behavior [39]. Moreover, other studies have shown a significant correlation between low-anxiety or increased exploratory behaviors and A concentration in the hippocampus [52]. Several studies developed in rodents show that $A$ and $P$ reduce stress and anxiety-like behavior [1,36,62-67]. In fact, the blockade of progesterone's conversion to its metabolites impairs social behavior and induces anxiety-related behavior in rats [68].

The SS arise as a promising solution to the poor bioavailability and rapid metabolism of natural NS administration [12], but it is necessary to compare their biological effects in similar targets and doses of the NS.

In this work, an anxiety model developed to identify the pharmacological mechanisms and potential clinical effects of synthetic and natural steroids was used. Usually, this kind of model based on conflict situations can generate opposite motivational states induced by approach-avoidance situations, however it does not attempt to replicate all features and symptoms of a specific anxiety disorder. Rather, it tries to generate a state of anxiety that could be related to these disorders. Another important methodological consideration that needs to be taken into account is our choice to cannulate animals in a unilateral way (with left/right alternations). Although bilateral cannulae have been widely used to explore the anxiolytic and antidepressant-like effects [46-48], we relied in reports that have not found behavioral differences describing these effects between the brain sides with unilateral progesterone or A microinfusions [49,50]. In 
agreement with this information, we do not observe lateral influence on the horizontal and vertical exploratory activities either.

Here, we evaluated the anxiolytic properties of an equal dose of A, P or two synthetic steroid analogues (Epoxy 1 and Epoxy 2) by microinfusions in dorsal hippocampus on the open-field test, quantifying horizontal and vertical exploration. The changes observed on the behavioral parameters by $\mathbf{A}$ and $\mathbf{P}$ can be interpreted as anxiolytic-like effects. Both natural NS enhanced the exploratory activity observed trough the Line crossing, Grooming and Rearing increases and Freezing decrease. However, in some cases $\mathrm{P}$ treatment produced the most potent anxiolytic-like effects. Although anxiolytic effects of $A$ are widely described in literature [69-72], only few reports have shown that $\mathbf{P}$ administration is able to produce similar effects $[28,36,57]$ with an improved efficacy in some cases [27].

Therefore, the results described in this work support these last findings and add more evidence to this topic. Moreover, none of the treatment affected the duration of Grooming and Rearing events observed through the absence of significant differences in their ratios.

Although $\mathrm{A}$ and $\mathrm{P}$ treatments produce a significant increase in the Active time and Line crossing, correlations analyses of Line crossing based Active time were not equal. Only a positive correlation of these parameters was observed with microinfusions of $\mathbf{P}$ or its analogue Epoxy 2. These differences may probably due to the molecular features of each steroid. These analyses allow to describe similar behavioral effects for steroids with similar A/B rings conformations and suggest that the SS and probably A doses should be administered in higher concentrations to probably produce anxiolytic-like effects. Although, these SS had a limited solubility in aqueous medium.

Previously, we described similar responses to $\mathbf{A}$ and $\mathbf{P}$ with these SS administrations in a variety of assays, including binding modulation of specific ligands to the $\mathrm{GABA}_{\mathrm{A}}$ receptor, the $3 \beta$-hydroxysteroid dehydrogenase activity alteration and neuroprotection in cerebral cortex and hippocampus cultures against a hypoxic event $[17,18]$. However, no effects were observed in these behavioral assays, we do not discard these SS for further in vivo evaluations that include another doses and more behavioral assays.

Summarizing, in this work we evaluated, in an open-field test, the in vivo anxiolytic-like effects of two synthetic analogues of $\mathrm{A}$ and $\mathrm{P}$ with a decreased molecular flexibility (that confers a favorable spatial arrangement for the steroid binding site). Only an increase in animal exploratory activities interpreted as anxiolytic-like effects were observed with $\mathrm{A}$ and $\mathrm{P}$ microinfusions. The lack of anxiolytic-like effect at the dose evaluated, and the previously reported modulation on the $\mathrm{GABA}_{\mathrm{A}}$ receptor $[17,18]$ may these SS suitable for therapeutical treatments in other mood disorders where the GABAergic function is involved like early chronic psychosocial stress or depression. Nevertheless the action of these Epoxies should be further evaluated for these conditions.

\section{Acknowledgment}

This work was supported by grants from ANPCYT PICT-2006-727; CONICET PIP-860, PIP-243 and partially supported by UBACYT. M R was supported by a fellowship from CONICET.

\section{References}

1. Lambert JJ, Belelli D, Peden DR, Vardy AW, Peters JA (2003) Neurosteroid modulation of GABAA receptors. Prog Neurobiol 71: 67-80.
2. Akk G, Covey DF, Evers AS, Steinbach JH, Zorumski CF, et al. (2009) The influence of the membrane on neurosteroid actions at GABA(A) receptors. Psychoneuroendocrinology 34 Suppl 1: S59-66.

3. Majewska MD (1992) Neurosteroids: endogenous bimodal modulators of the GABAA receptor. Mechanism of action and physiological significance. Prog Neurobiol 38: 379-395.

4. Reddy DS (2003) Is there a physiological role for the neurosteroid THDOC in stress-sensitive conditions? Trends Pharmacol Sci 24: 103-106.

5. Gasior M, Carter RB, Witkin JM (1999) Neuroactive steroids: potential therapeutic use in neurological and psychiatric disorders. Trends Pharmacol Sci 20: 107-112.

6. Rupprecht R, di Michele F, Hermann B, Ströhle A, Lancel M, et al. (2001) Neuroactive steroids: molecular mechanisms of action and implications for neuropsychopharmacology. Brain Res Brain Res Rev 37: 59-67.

7. Mellon SH (2004) Synthesis, enzyme localization, and regulation of neurosteroids. In: Smith SS Editor. Neurosteroid effects in the central nervous system: the role of the GABAA receptor. Boca Raton: CRC Press $1-46$.

8. Dubrovsky BO (2005) Steroids, neuroactive steroids and neurosteroids in psychopathology. Prog Neuropsychopharmacol Biol Psychiatry 29: 169-192.

9. Hirst JJ, Kelleher MA, Walker DW, Palliser HK (2014) Neuroactive steroids in pregnancy: key regulatory and protective roles in the foetal brain. J Steroid Biochem Mol Biol 139: 144-153.

10. Akk G, Covey DF, Evers AS, Steinbach JH, Zorumski CF, et al. (2007) Mechanisms of neurosteroid interactions with GABA(A) receptors. Pharmacol Ther 116: 35-57.

11. Reddy DS (2010) Neurosteroids: endogenous role in the human brain and therapeutic potentials. Prog Brain Res 186: 113-137.

12. Rey M, Coirini H (2015) Synthetic neurosteroids on brain protection. Neural Regen Res 10: 17-21.

13. Purdy RH, Morrow AL, Blinn JR, Paul SM (1990) Synthesis, metabolism, and pharmacological activity of 3a-hydroxy steroids which potentiate GABA-receptor-mediated chloride ion uptake in rat cerebral cortical synaptoneurosomes. J Med Chem 33: 1572-1581.

14. Souli C, Avlonitis N, Calogeropoulou T, Tsotinis A, Maksay G, et al. (2005) Novel 17beta-substituted conformationally constrained neurosteroids that modulate GABA A receptors. J Med Chem 48: 5203-5214.

15. Scaglione JB, Manion BD, Benz A, Taylor A, DeKoster GT, et al. (2006) Neurosteroid analogues. 11. Alternative ring system scaffolds: gammaaminobutyric acid receptor modulation and anesthetic actions of benz[f]indenes. J Med Chem 49: 4595-4605.

16. Suñol C, García DA, Bujons J, Kristofíková Z, Matyás L, et al. (2006) Activity of B-nor analogues of neurosteroids on the GABA(A) receptor in primary neuronal cultures. J Med Chem 49: 3225-3234.

17. Rey M, Kruse MS, Alvarez LD, Ghini AA, Veleiro AS, et al. (2013) Neuroprotective action of synthetic steroids with oxygen bridge. Activity on GABAA receptor. Exp Neurol 249: 49-58.

18. Rey M, Veleiro AS, Ghini AA, Kruse MS, Burton G, et al. (2015) Effect of synthetic steroids on GABAA receptor binding in rat brain. Neuroscience 290: 138-146.

19. Veleiro AS, Burton G (2009) Structure-activity relationships of neuroactive steroids acting on the GABAA receptor. Curr Med Chem 16: 455-472.

20. Norberg L, Wahlström G, Bäckström T (1987) The anaesthetic potency of 3 alpha-hydroxy-5 alpha-pregnan-20-one and 3 alpha-hydroxy-5 betapregnan-20-one determined with an intravenous EEG-threshold method in male rats. Pharmacol Toxicol 61: 42-47.

21. Belelli D, Lan NC, Gee KW (1990) Anticonvulsant steroids and the GABA/benzodiazepine receptor-chloride ionophore complex. Neurosci Biobehav Rev 14: 315-322. 
22. Wieland S, Lan NC, Mirasedeghi S, Gee KW (1991) Anxiolytic activity of the progesterone metabolite 5 alpha-pregnan-3 alpha-o1-20-one. Brain Res 565: 263-268.

23. Devaud LL, Purdy RH, Morrow AL (1995) The neurosteroid, 3 alphahydroxy-5 alpha-pregnan-20-one, protects against bicuculline-induced seizures during ethanol withdrawal in rats. Alcohol Clin Exp Res 19: 350-355.

24. Picazo O, Fernández-Guasti A (1995) Anti-anxiety effects of progesterone and some of its reduced metabolites: an evaluation using the burying behavior test. Brain Res 680: 135-141.

25. Wang MD, Wahlström G, Gee KW, Bäckström T (1995) Potency of lipid and protein formulation of 5 alpha-pregnanolone at induction of anaesthesia and the corresponding regional brain distribution. $\mathrm{Br} \mathrm{J}$ Anaesth 74: 553-557.

26. Weiland NG, Orchinik M (1995) Specific subunit mRNAs of the GABAA receptor are regulated by progesterone in subfields of the hippocampus. Brain Res Mol Brain Res 32: 271-278.

27. Wieland S, Belluzzi JD, Stein L, Lan NC (1995) Comparative behavioral characterization of the neuroactive steroids 3 alpha-OH,5 alphapregnan-20-one and 3 alpha-OH,5 beta-pregnan-20-one in rodents. Psychopharmacology (Berl) 118: 65-71.

28. Carboni E, Wieland S, Lan NC, Gee KW (1996) Anxiolytic properties of endogenously occurring pregnanediols in two rodent models of anxiety. Psychopharmacology (Berl) 126: 173-178.

29. Finn DA, Roberts AJ, Lotrich F, Gallaher EJ (1997) Genetic differences in behavioral sensitivity to a neuroactive steroid. J Pharmacol Exp Ther 280: 820-828.

30. Palmer AA, Miller MN, McKinnon CS, Phillips TJ (2002) Sensitivity to the locomotor stimulant effects of ethanol and allopregnanolone is influenced by common genes. Behav Neurosci 116: 126-137.

31. Bitran D, Hilvers RJ, Kellogg CK (1991) Anxiolytic effects of 3 alphahydroxy-5 alpha[beta]-pregnan-20-one: endogenous metabolites of progesterone that are active at the GABAA receptor. Brain Res 561: 157-161.

32. Bitran D, Purdy RH, Kellogg CK (1993) Anxiolytic effect of progesterone is associated with increases in cortical allopregnanolone and GABAA receptor function. Pharmacol Biochem Behav 45: 423-428.

33. Fernández-Guasti A, Picazo O (1995) Flumazenil blocks the anxiolytic action of allopregnanolone. Eur J Pharmacol 281: 113-115.

34. Brot MD, Akwa Y, Purdy RH, Koob GF, Britton KT (1997) The anxiolyticlike effects of the neurosteroid allopregnanolone: interactions with GABA(A) receptors. Eur J Pharmacol 325: 1-7.

35. Reddy DS, Kulkarni SK (1997) Differential anxiolytic effects of neurosteroids in the mirrored chamber behavior test in mice. Brain Res 752: 61-71.

36. Bitran D, Dugan M, Renda P, Ellis R, Foley M (1999) Anxiolytic effects of the neuroactive steroid pregnanolone (3 alpha-OH-5 beta-pregnan-20one) after microinjection in the dorsal hippocampus and lateral septum. Brain Res 850: 217-224.

37. Rupprecht R (2003) Neuroactive steroids: mechanisms of action and neuropsychopharmacological properties. Psychoneuroendocrinology 28: 139-168.

38. Bannerman DM, Rawlins JN, McHugh SB, Deacon RM, Yee BK, et al. (2004) Regional dissociations within the hippocampus--memory and anxiety. Neurosci Biobehav Rev 28: 273-283.

39. Mòdol L, Darbra S, Pallarès M (2011) Neurosteroids infusion into the CA1 hippocampal region on exploration, anxiety-like behaviour and aversive learning. Behav Brain Res 222: 223-229.

40. Pick CG, Peter Y, Terkel J, Gavish M, Weizman R (1996) Effect of the neuroactive steroid alpha-THDOC on staircase test behavior in mice. Psychopharmacology (Berl) 128: 61-66.

41. Mok WM, Krieger NR (1990) Evidence that 5 alpha-pregnan-3 alphaol-20-one is the metabolite responsible for progesterone anesthesia. Brain Res 533: 42-45.
42. Bitran D, Mc Leod M, Schiekh M (1995) Blockade of the bioconversion of progesterone to allopregnanolone prevents the anxiolytic effects and potentiation of cortical GABAA receptor function observed in progesterone treated ovariectomized rats. Soc Neurosci Abstr 19: 373-379

43. Eduardo SL, Ghini AA, Burton G (2003) Oxido-bridged neurosteroid analogues Synthesis of 2,19-oxido-allopregnanolone. ARKIVOC X: 468-476

44. Veleiro AS, Rosenstein RE, Jaliffa CO, Grilli ML, Speroni F, et al. (2003) Synthesis and GABA(A) receptor activity of a 6,19-oxido analogue of pregnanolone. Bioorg Med Chem Lett 13: 343-346.

45. Paxinos G, Watson C (1998) The rat brain in stereotaxic coordinates (4thedn) Academic Press, San Diego California.

46. Engin E, Treit D (2007) The anxiolytic-like effects of allopregnanolone vary as a function of intracerebral microinfusion site: the amygdala, medial prefrontal cortex, or hippocampus. Behav Pharmacol 18: 461-470.

47. Frye CA, Paris JJ, Rhodes ME (2008) Estrogen is necessary for 5alphapregnan-3alpha-ol-20-one (3alpha,5alpha-THP) infusion to the ventral tegmental area to facilitate social and sexual, but neither exploratory nor affective behavior of ovariectomized rats. Pharmacol Biochem Behav 91: 261-270.

48. Nin MS, Salles FB, Azeredo LA, Frazon AP, Gomez R, et al. (2008) Antidepressant effect and changes of GABAA receptor gamma2 subunit mRNA after hippocampal administration of allopregnanolone in rats. J Psychopharmacol 22: 477-485.

49. Rodríguez-Landa JF, Contreras CM, Bautista-Martínez FE, Saavedra M, Bernal-Morales B, et al. (2005) Antidepressant-like effect of a microinjection of allopregnanolone in the dorsal hippocampus and lateral septal nucleus in the rat; involvement of GABAA receptor. Behav Pharmacol 16: S45.

50. Estrada-Camarena E, Contreras CM, Saavedra M, Luna-Baltazar I, López-Rubalcava C (2002) Participation of the lateral septal nuclei (LSN) in the antidepressant-like actions of progesterone in the forced swimming test (FST). Behav Brain Res 134: 175-183.

51. Blizard DA, Lippman HR, Chen JJ (1975) Sex differences in open-field behavior in the rat: the inductive and activational role of gonadal hormones. Physiol Behav 14: 601-608.

52. Frye CA, Petralia SM, Rhodes ME (2000) Estrous cycle and sex differences in performance on anxiety tasks coincide with increases in hippocampal progesterone and 3alpha,5alpha-THP. Pharmacol Biochem Behav 67: 587-596.

53. McCarthy MM, Felzenberg E, Robbins A, Pfaff DW, Schwartz-Giblin S (1995) Infusions of diazepam and allopregnanolone into the midbrain central gray facilitate open-field behavior and sexual receptivity in female rats. Horm Behav 29: 279-295.

54. Schumacher M, Coirini H, Pfaff DW, McEwen BS (1990) Behavioral effects of progesterone associated with rapid modulation of oxytocin receptors. Science 250: 691-694.

55. Woods JH, Katz JL, Winger G (1992) Benzodiazepines: use, abuse, and consequences. Pharmacol Rev 44: 151-347.

56. Sperk G, Schwarzer C, Tsunashima K, Fuchs K, Sieghart W (1997) $\mathrm{GABA}(\mathrm{A})$ receptor subunits in the rat hippocampus I: immunocytochemical distribution of 13 subunits. Neuroscience 80: 987-1000.

57. Gomez C, Saldivar-Gonzalez A, Delgado G, Rodriguez R (2002) Rapid anxiolytic activity of progesterone and pregnanolone in male rats. Pharmacol Biochem Behav 72: 543-550.

58. Schüle C, Eser D, Baghai TC, Nothdurfter C, Kessler JS, et al. (2011) Neuroactive steroids in affective disorders: target for novel antidepressant or anxiolytic drugs? Neuroscience 191: 55-77.

59. Zheng P (2009) Neuroactive steroid regulation of neurotransmitter release in the CNS: action, mechanism and possible significance. Prog Neurobiol 89: 134-152.

60. Gago N, El-Etr M, Sananès N, Cadepond F, Samuel D, et al. (2004) 3alpha,5alpha-Tetrahydroprogesterone (allopregnanolone) and gammaaminobutyric acid: autocrine/paracrine interactions in the control of 
Citation: $\quad$ Rey M, Ghini AA, Coirini H (2016) Synthetic Epoxy-Pregnan Steroids: Effects on Anxiety Behavior in Rats. J Steroids Horm Sci 7: 167. doi:10.4172/2157-7536.1000167

Page 8 of 8

neonatal PSA-NCAM+ progenitor proliferation. J Neurosci Res 78: 770-783.

61. Harrison NL, Simmonds MA (1984) Modulation of the GABA receptor complex by a steroid anaesthetic. Brain Res 323: 287-292.

62. Majewska MD, Harrison NL, Schwartz RD, Barker JL, Paul SM (1986) Steroid hormone metabolites are barbiturate-like modulators of the GABA receptor. Science 232: 1004-1007.

63. Belelli D, Peden DR, Rosahl TW, Wafford KA, Lambert JJ (2005) Extrasynaptic GABAA receptors of thalamocortical neurons: a molecular target for hypnotics. J Neurosci 25: 11513-11520.

64. Martín-García E, Pallarès M (2005) Intrahippocampal nicotine and neurosteroids effects on the anxiety-like behaviour in voluntary and chronic alcohol-drinking rats. Behav Brain Res 164: 117-127.

65. Frye CA, Rhodes ME (2006) Infusions of 5alpha-pregnan-3alpha-ol-20one (3alpha,5alpha-THP) to the ventral tegmental area, but not the substantia nigra, enhance exploratory, anti-anxiety, social and sexual behaviours and concomitantly increase 3alpha,5alpha-THP concentrations in the hippocampus, diencephalon and cortex of ovariectomised oestrogen-primed rats. J Neuroendocrinol 18: 960-975.
66. Darbra $S$, Pallarès $M(2010)$ Alterations in neonatal neurosteroids affect exploration during adolescence and prepulse inhibition in adulthood. Psychoneuroendocrinology 35: 525-535.

67. Frye CA, Paris JJ (2011) Progesterone turnover to its 5ît-reduced metabolites in the ventral tegmental area of the midbrain is essential for initiating social and affective behavior and progesterone metabolism in female rats. J Endocrinol Invest 34: e188-199.

68. Finn DA, Roberts AJ, Long S, Tanchuck M, Phillips TJ (2003) Neurosteroid consumption has anxiolytic effects in mice. Pharmacol Biochem Behav 76: 451-462.

69. Bäckström T, Bixo M, Johansson M, Nyberg S, Ossewaarde L, et al. (2014) Allopregnanolone and mood disorders. Prog Neurobiol 113: 88-94.

70. Bali A, Jaggi AS (2014) Multifunctional aspects of allopregnanolone in stress and related disorders. Prog Neuropsychopharmacol Biol Psychiatry 48: 64-78.

71. Melcangi RC, Panzica GC (2014) Allopregnanolone: state of the art. Prog Neurobiol 113: 1-5.

72. Schüle C, Nothdurfter C, Rupprecht R (2014) The role of allopregnanolone in depression and anxiety. Prog Neurobiol 113: 79-87. 